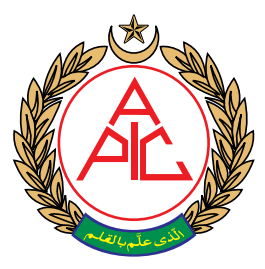

Corrective exercise specialist, Training \& Rehabilitation, Oslo Norway

${ }^{2}$ Director of pain management, Ventura County Medical Center Ventura, CA 93003, USA.

Correspondence: Kjetil Larsen, CES, Corrective Exercise Specialist, Training \& Rehabilitation, Oslo Norway; Kjetil@trainingandrehabilitation. com;

Tel.: +4797545192

Received: 23 November 2018

Reviewed \& Accepted: 28

February 2019

\section{Lumbosacral plexus entrapment syndrome. Part one: A common yet little-known cause of chronic pelvic and lower extremity pain}

\author{
Kjetil Larsen, CES, George C. Chang Chien, D O²
}

\begin{abstract}
Lumbosacral plexus entrapment syndrome (LPES) is a little-known but common cause of chronic lumbopelvic and lower extremity pain. The lumbar plexus, including the lumbosacral tunks emerge through the fibers of the psoas major, and the proximal sciatic nerve beneath the piriformis muscles. Severe weakness of these muscles may lead to entrapment plexopathy, resulting in diffuse and non-specific pain patterns throughout the lumbopelvic complex and lower extremities (LPLE), easily mimicking other diagnoses and is therefore likely to mislead the interpreting clinician. It is a pathology very similar to that of thoracic outlet syndrome, but for the lower body. This two part manuscript series was written in an attempt to demonstrate the existence, pathophysiology, diagnostic protocol as well as interventional strategy for LPES, and its efficacy.
\end{abstract}

Key words: Pelvic girdle; Pain, Pelvic girdle; Lumbosacral plexus entrapment syndrome; Piriformis syndrome; Nerve entrapment; Double-crush; Pain, Chronic; Fibromyalgia

Citation: Larsen K, Chien GCC. Lumbosacral plexus entrapment syndrome. Part one: A common yet little-known cause of chronic pelvic and lower extremity pain. Anaesth pain \& intensiv care $2019 ; 23(2): 124-137$

\section{INTRODUCTION}

Chronic pelvic and lower extremity pain is widespread, affecting up to $26,6 \%$ of women, thus having a great socioeconomical impact. ${ }^{1}$ Many potential etiologies have been proposed for chronic pelvic pain, some examples being sacroiliac joint dysfunction, ${ }^{2,3}$ nerve root and facet joint referred pain. ${ }^{4,5}$ However, because its symptomology tend to be diffuse in nature, often not compatible with mere sacroiliac, root dermatome or myogenic explanations, the patient's maladies may be considered idiopathic or rendered "fibromyalgic". ${ }^{6}$

Indeed, several etiologies of pain may be present simultaneously, but it is our impression, after numerous examinations of this patient group that there is staggering a prevalence of lumbopelvic and lower extremity (LPLE) nerve sensitivity amongst the majority of LPLE nervous branches, detected with Tinel's test (i.e. provocative pressure applied directly onto the nerve in question), ${ }^{7}$ suggesting underlying entrapment neuropathy. The etiology of this phenomenon is hereby proposed to be lumbosacral entrapment syndrome (LPES), a problem involving entrapment of the lumbosacral plexuses within their emergent passages in the lumbopelvic complex, similar to thoracic outlet syndrome (TOS) in the upper body. This manuscript aims to outline the existence, symptoms, diagnostic criteria and treatment protocol to address LPES. LPES can be treated conservatively with pleasing results if appropriately identified and treated.

\section{LUMBOSACRAL PLEXUS ENTRAPMENT SYNDROME}

Lumbosacral plexus entrapment syndrome involves entrapment of the lumbar plexus, lumbosacral trunk and proximal sciatic nerve within the psoas major and piriformis due to chronic weakness or injury of these muscles. ${ }^{8}$ It may result in diffuse but often debilitating symptoms in the pelvis and lower extremities.

There have been several mentions of lumbar plexopathy in the literature. However most of these are not considered to be of "MSK" territory nor 
origin. Pregnancy, both antepartum, intrapartum and postpartum (compression caused by the fetus), ${ }^{9}$ hematomas, ${ }^{10,11}$ aneurysms, ${ }^{12}$ trauma, ${ }^{13}$ tumors, ${ }^{13}$ abscesses, ${ }^{14}$ cysts, ${ }^{15}$ cancer, ${ }^{16,17}$ and iatrogenesis, ${ }^{18}$ are all rare, but known causes of this problem. Also known, but often not considered in clinical practice, is the fact that the entire lumbar plexus including the lumbosacral trunk emerges through the myofascia of the psoas major muscle ${ }^{19,20,21}$ and may become entrapped within it, resulting in various degrees of lumbosacral plexopathy. ${ }^{8}$ Further, a debated topic, but well-known nonetheless, is the notion that the proximal sciatic nerve may become entrapped underneath the piriformis muscle, ${ }^{22,23,24}$ and along with pre-entrapment of the lumbosacral trunk and lumbar plexus, these factors, in tandem, form the rationale for LPES. Empirically, dysfunction of the psoas major and piriformis almost invariably codevelop, especially in non-traumatic incidences. Thus, for the most part, lumbar and sacral entrapment plexopathies are viewed as one united problem throughout this article.

There is scarce literature with regards to myogenic, i.e. myofascially induced lumbar plexus entrapment, and therefore some jumping between different entrapment pathologies is necessary in attempt to demonstrate several important points throughout this article. Further, because TOS is a problem whose mechanism is very similar to that of LPES, but is much more renowned, several references will be made to TOS-relevant literature.

LPES may, in fact, be regarded as "the thoracic outlet syndrome of the lower body". It is a "double crush", i.e. multifocal nerve entrapment neuropathy, ${ }^{25-34}$ often resulting in diffuse neuralgic patterns difficult to pinpoint in the LPLE. ${ }^{9,39,40}$ Other frequently used terms for this problem is "Maigne's syndrome", 35 "thoracolumbar junction syndrome", 36 "dorsal ramus syndrome", 37,38 and "piriformis syndrome", which are, in our impression, different perceptions of the same hierarchical problem, as they are frequently seen in tandem. ${ }^{8}$ Entrapment of the lumbar plexus may cause radiative "aches" in one or several of its branches, and may also affect the sciatic nerve and sacral plexus due to their anastomosis through the lumbosacral trunk as well as proximal sciatic entrapment by the piriformis muscle. Entrapment occurring at these proximal segments may greatly predispose and sensitize the intermediate and distal nervous branches throughout the LPLE, due to the "double crush" phenomenon, often producing seemingly focally originating symptoms.

A patient who is severely afflicted by LPES may frequently feel that "everything" hurts or is tender, and may often be misdiagnosed with fibromyalgia or psychogenicity. However, upon provocative palpation of the nerve-passages (Tinel's test), significant pain may be elicited, whereas tissues medial or lateral to the nerve tested, are significantly less tender, suggesting occult neuralgia rather than fibromyalgia as the etiology. ${ }^{8}$ Just like TOS is notoriously difficult to diagnose and treat due to its nonspecific presentation, $41,42,43,44,45,46,47,48$ LPES is a similar condition. LPES may frequently present with distal symptoms, likely to mislead the practitioner. For example, similarly, it is known that TOS patients may present with seemingly unrelated symptoms, such as carpal tunnel syndrome, ${ }^{49}$ chest pain ${ }^{50}$ shoulder pain, ${ }^{51}$ brachialgia, ${ }^{52}$ or periscapular pain. ${ }^{53}$ Entrapmentinduced dysautonomia has also been implicated in TOS. ${ }^{54,55}$ The presentation of LPES may be similar in mimicking other, seemingly unrelated pathologies, such as one or more of the following:

- Low back pain (dorsal ramus nerves)

- Groin and testicular/ labial pain (genitofemoral or pudendal neuralgia)

- Pelvic floor and genital pain (pudendal neuralgia)

- Sacroiliac pain (medial cluneal neuralgia)

- Abdominal flank, hypogastric and inguinal pains (ilioinguinal and iliohypogastric neuralgia)

- Iliac crest/gluteus medius pain (superior cluneal neuralgia)

- Buttock pain (sciatic \& gluteal neuralgias)

- Hamstring pain (sciatic neuralgia)

- Plantar fasciitis (tibial neuralgia)

- Calf pain (tibial neuralgia)

- Lateral calf pain (peroneal neuralgia)

- Lateral thigh pain (meralgia paresthetica (lateral femoral cutaneous neuralgia))

- Anterior thigh pain (femoral nerve)

- Medial knee pain (saphenous neuralgia)

- Medial shin pain (saphenous neuralgia)

- Diffuse dysautonomic symptoms and neuralgias can sometimes also occur, such as complex regional pain syndrome, bladder incompetence, overactive bladder, prostate pain, slowed bowel movements etc.

- Coccydynia (most likely due neuralgic spreading to the coccygeal plexus)

Understanding the symptoms of LPES is crucial in order for the practitioner to perform the appropriate tests, leading to a correct diagnosis. The symptoms of lesser to moderate forms of LPES, as suggested, may present as seemingly focal and unrelated pathologies which may differ from patient to patient, but the clinician will still be able to demonstrate severe palpation tenderness upon applying Tinel's test to most LPLE branches, suggesting (presuming that other causes have been excluded) subtle (myogenic) plexopathy with secondary peripheral sensitization. 


\section{PATHOGENESIS}

Lumbosacral plexus entrapment syndrome is caused by entrapment of the lumbar plexus, lumbosacral trunk and proximal sciatic nerves within the psoas major and piriformis muscles, when these are impaired. The cause, and even definition of impairment, however, is an opinionated topic. Again, some jumping between issues is necessary to provide citations which may illuminate the question at hand.

A commonly accepted notion is that TOS and piriformis syndrome (PS) are caused by overuse and hypertrophy of the scalenus anticus and piriformis muscles. ${ }^{24,56,57,58,59,60,61,62,63,64}$ However, if this was the sole cause, then one would expect daily stretching, massaging, or at least surgical resection of the hypertrophic tissue to resolve the problem. This, however, has not turned out to be the case. Contrarily, Hopayian et al. state, in their systematic review, ${ }^{24}$ regarding piriformis syndrome, that this problem has been described for the last 70 years, yet it remains controversial, as it could be argued that there is no value in diagnosing a problem which has no proven treatment. Regarding conservative treatment of TOS, Vanti et al. state, in their review ${ }^{60}$ that there is no consensus with regards conservative treatment of TOS, e.g. as to what should be stretched and what should be strengthened. It is also well known that long-term outcomes out surgical intervention for TOS have variable outcomes at best. ${ }^{65,66,67,68,69}$ Could it be that the lack of consensus, as well as beneficial treatment outcomes are a result of fundamental pathophysiological misconceptions? Is it likely, based on both the evidence as well as empirical data, that "overactive" and "overly strong" muscles cause nerve entrapments? Inevitably, a misconceived etiological perspective would negatively affect both diagnostic criteria as well as treatment outcomes.

Digging deeper, research has shown that painful areas may develop myofascial hypertrophy with fatty infiltration (atrophy), ${ }^{72,73,74,75,80,79}$ implying that these thickened muscles, in reality, may be injured and tremendously weak. Elliott ${ }^{75}$ showed that whiplash patients tend to develop hypertrophywith concomitant atrophy of the cervical muscles. Langevin ${ }^{72}$ showed that low back pain sufferers might develop up to $25 \%$ thicker thoracodorsal fascia than controls, despite the well-known prevalence of paraspinal erector atrophy in LBP patients. ${ }^{76}$ Stecco ${ }^{77,78}$ showed that the degree of thickness correlated with pain levels and that the affected muscle's fascia rigidizes due to a buildup of hyaluronic acid. Massoud ${ }^{79}$ demonstrated that hypertrophied gluteus maximus muscles in sacroiliac joint dysfunction (SIJD) were hypertrophied upon inspection, yet proven very weak upon strength testing. Similarly, Mooney ${ }^{80}$ demonstrated gluteal EMG hyperactivity of the gluteus maximus on the symptomatic side of SIJD, however, and interestingly, after improving gluteal strength, its excess EMG signal output normalized (i.e. reduced), indicating that EMG overactivity may be a sign of muscle inadequacy and not necessarily a sign of domination, as it is generally considered. Thus, increased muscle thickness \& activity in the co-presence of pain may indicate underlying weakness and injury of that structure. Certainly, a thickened structure with high EMG output, but later proven weak, is very counterintuitive. But, these findings may aid in explaining why many seemingly logical approaches to disengage (massages, stretching, needling etc.) "overactive" culprit muscles, e.g. the piriformis muscle, repeatedly fail in providing long-term relief in the treatment of entrapment neuropathies. Moreover, MR imaging of the culprit muscle's tendons may frequently reveal tendinous hypointensity consistent with chronic degeneration as opposed to dominance, as will be discussed in detail in the "Imaging" section.

Therefore, with regards to the mechanism of pathology, impaired muscular structures such as the psoas major, piriformis, or similar may develop fascial fibrosis and subsequent rigidity as a result of chronic inadequacy and overburdening, irritating its intimately traversing nerves, resulting in entrapment neuropathy. The notion that weak muscles, rather than overly strong and dominant muscles are the culprit, carries a greater sense of logic. Why would strength be a liability? Then, rather than performing never-ending myofascial release (MFR) in the hope of disengaging the "fiendish muscle", a strategy which has repeatedly proven not to be an effective long-term intervention for entrapment neuropathies, a simple and inexpensive approach of muscle strengthening may be carried out instead.

\section{DIAGNOSTIC CRITERIA}

If plexopathy is suspected, central spinal stenosis, lumbar root compressions, adjacent masses, systematic etiologies such as diabetes or autoimmunity, and similar causes of neuropathy should be excluded first. Amongst the former, radiculopathy is perhaps the most common differential diagnosis. Thankfully, it is relatively simple to distinguish between LPES and radiculopathy, as the patient will have pain "everywhere" upon provocation with Tinel's test, and is thus not compatible with mere dermatome pain patterns which would present in radiculopathies. The diagnosis of LPES is made based on three main criteria; clinical symptoms, Tinel's tests, and myotome tests. MR images can also be evaluated, but it is not necessary to make the diagnosis. Electrodiagnostic assessments, which will be elaborated upon in the "Neurography" section, are generally not helpful for diagnosis nor exclusion of LPES. 
Tinel's test, however, is a useful and straightforward provocative test for detecting LPES, only requiring that the clinician is [well] acquainted with the anatomy and understands how to interpret the patient's response. In LPES, most nervous branches will be affected and very sensitive upon palpation, at least in the chronic sufferer. There are ten main areas to which we will apply the Tinel's provocative pressure test, involving branches of the cluneal, femoral, peroneal, sciatic, obturator and saphenous nerves. For each pressure point, a firm squeeze is applied onto the nerve by the practitioner's thumb. The patient will be asked to grade each area with a 0-10 numeric rating scale (NRS). 5 or more areas of $>$ 7 NRS is strongly indicative of LPES. Pain elicitation $<5$ NRS should generally not be considered as pathological, although it does indicate some minor degree of irritation. Healthy nerves should not hurt upon palpation, even when squeezed. This may sound unbelievable to some, but will quickly be evident when using these tests (figures 1-9) in a clinical setting, with various patients. The locations and degree of pain elicitation will vary depending on which pathologies are present. Often, no pain will be elicited at all, despite hard manual pressures, contrary to common belief.

It is important to emphasize that proximal entrapment within the psoas major and piriformis muscles will cause both proximal and distal nerve sensitivity. The reason why distal branches of the nerves are also being tested for irritation, is both to evaluate the degree of segmental irritation as well as estimate whether or not focal numbness may be present, as the latter is indicative of significant peripheral nerve compression. Generally, an entrapped and irritated nerve will be sensitive to touch. However, localized numbness may occur in the presence of substantial compression, sometimes giving the impression that the test is negative due to focal sensory loss. This will usually happen in spaces where body dynamics, mainly hip flexion, stretches the muscle which is irritating the affected nerve, furthering its compression. In such cases, compatible symptoms will be present (e.g. meralgia paresthetica), yet the nerve (e.g. LFCN) proves painless when applying provocative pressure.

In the relevance of LPES, there are two areas that should be noted, as they are frequently hypoesthetic due to focal compressive forces:

- The inguinal ligament: Maximal hip flexion may cause a weak $\&$ tight pectineus muscle to lift the femoral, lateral cutaneous and genitofemoral nerves into the inguinal ligament, compressing them, causing local sensory numbness.

- The piriformis muscle/proximal sciatic nerve:
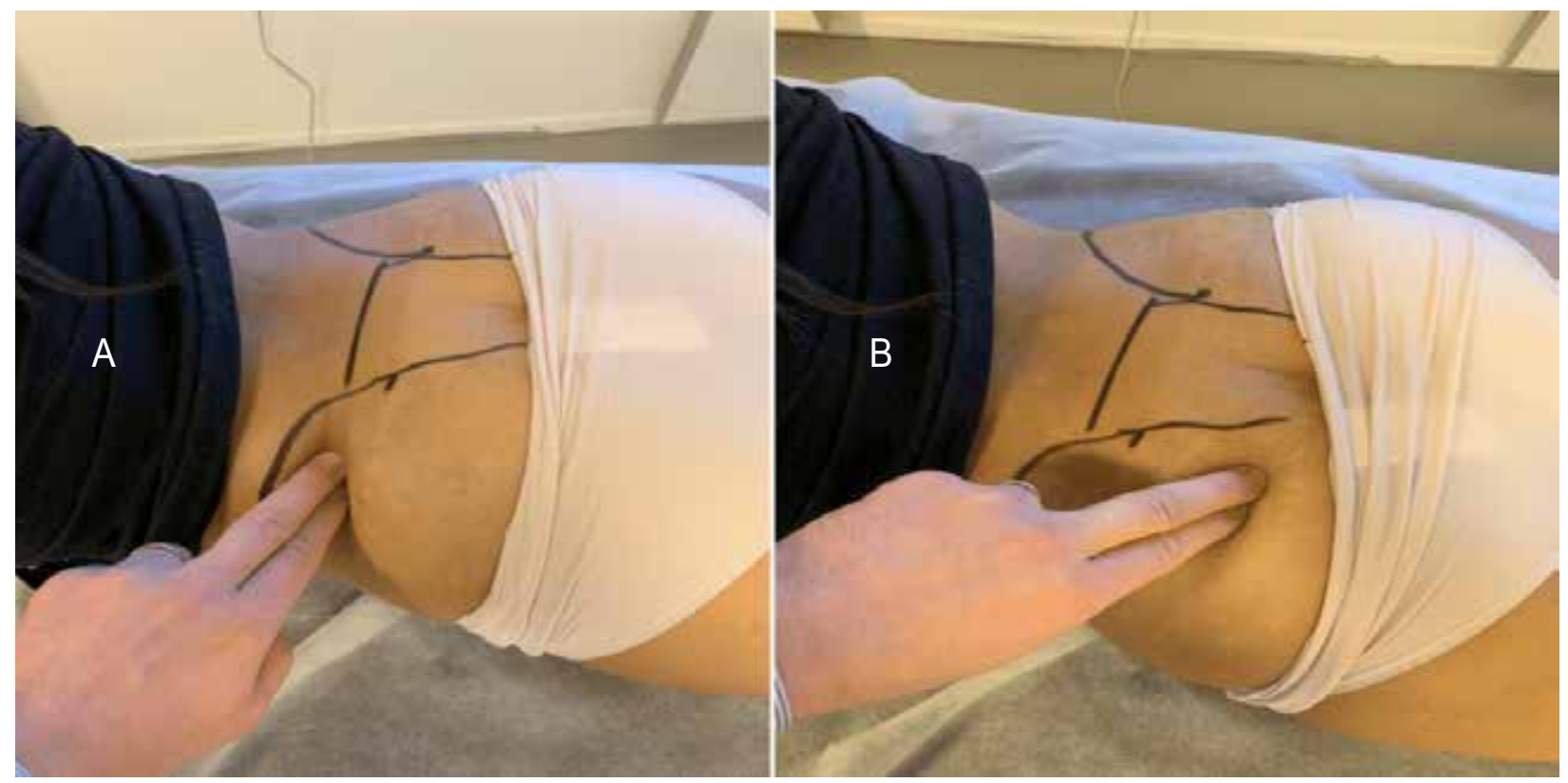

Figure 1: Tinel's test of the superior (left) and middle (right) cluneal nerves. For the superior part, identify the posterior iliac crest approximately one to two inches lateral to the posterior superior iliac spine (PSIS). For the middle cluneal nerve, track the iliac crest medially until the superolateral surface of the sacrum. Apply ventrally directed pressure. 


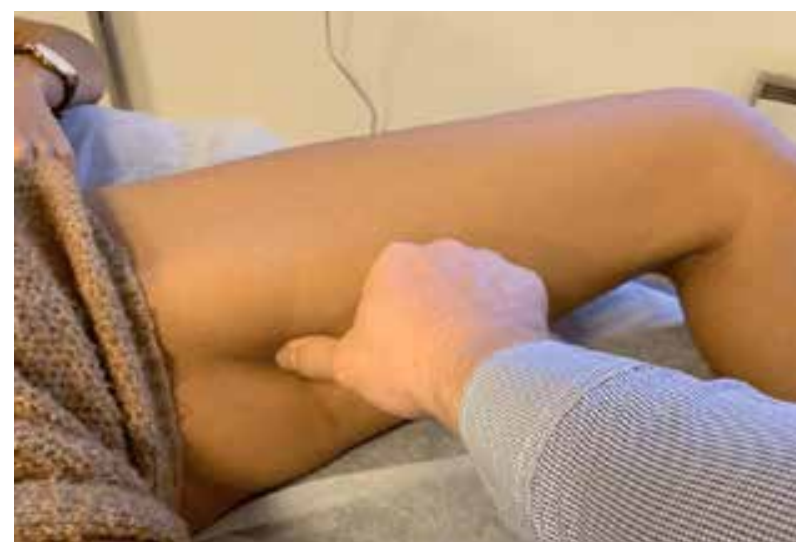

Figure 2: Tinel's test of the obturator nerve. Identify the adductor magnus, directly posterior to the adductor longus, and apply force directed toward the diaphysis

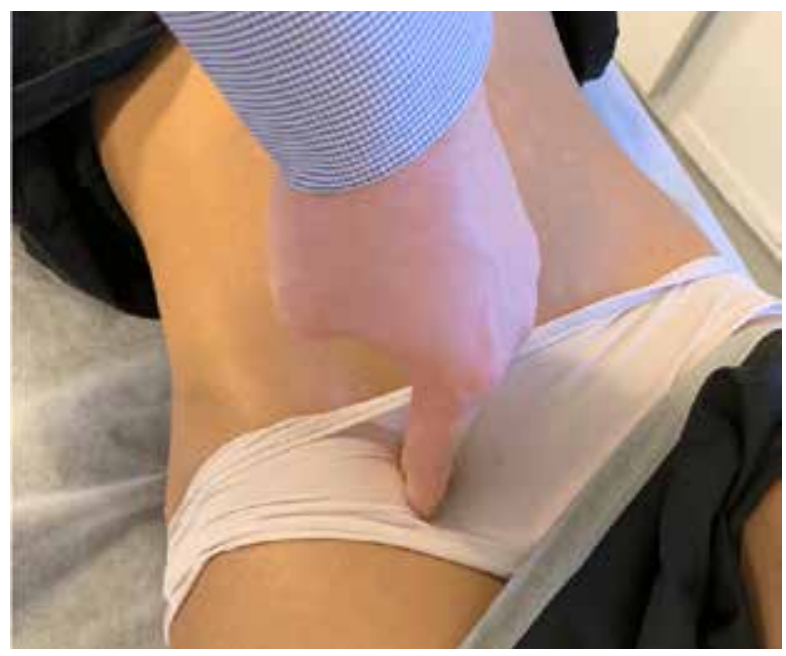

Figure 3: Tinel's test of the femoral, genitofemoral (GFN) and lateral femoral cutaneous (LCFN) nerves. Identify the inguinal ligament, and apply dorsally directed force. Tracking the ligament laterally will be more specific to the LFCN, while medially, the GFN

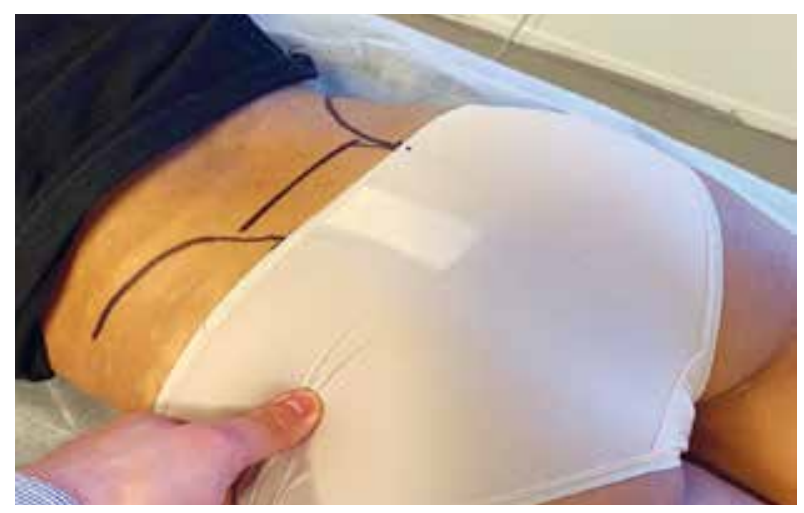

Figure 4: Tinel's test of the proximal sciatic nerve. Identify the greater trochanter and lateral surface of the sacrum, apply pressure to the mid-point, directed to the piriformis muscle and proximal sciatic nerve

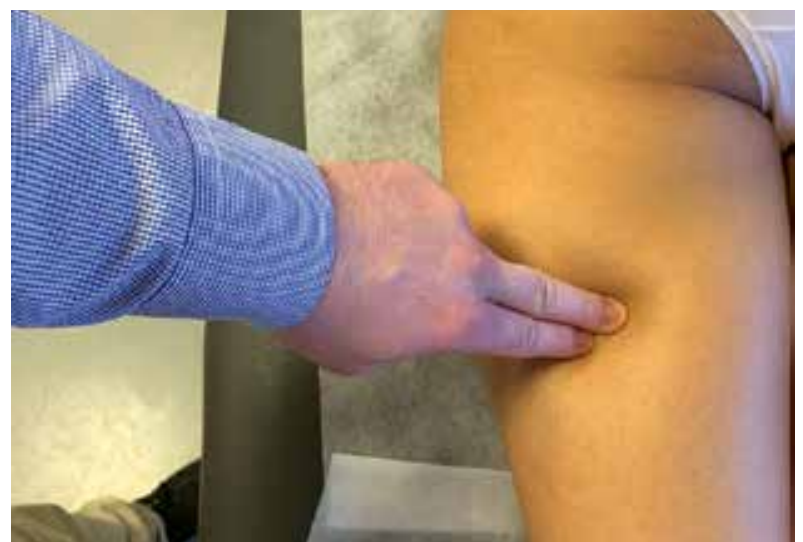

Figure 5: Tinel's test of the intermediate sciatic nerve segment. The nerve transmits beneath the biceps femoris. Apply direct ventral force toward the mid-diaphysis either from the median or lateralparamedian areas of the posterior thigh.

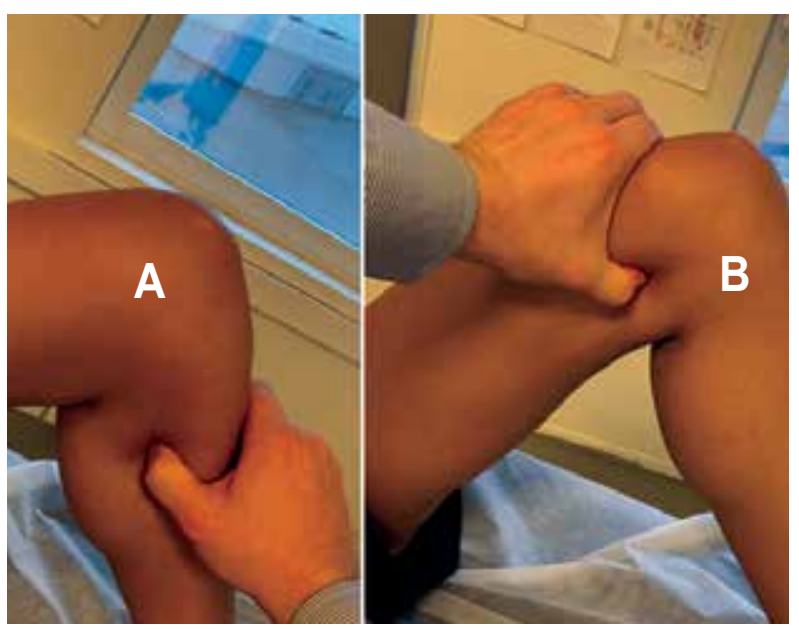

Figure 6: Tinel's test of the saphenous nerve. The saphenous nerve may be palpated medial to the vastus medialis, superior to the femoral condyle, and at the medial tibial diaphysis. Firm, medioventral pressure is applied

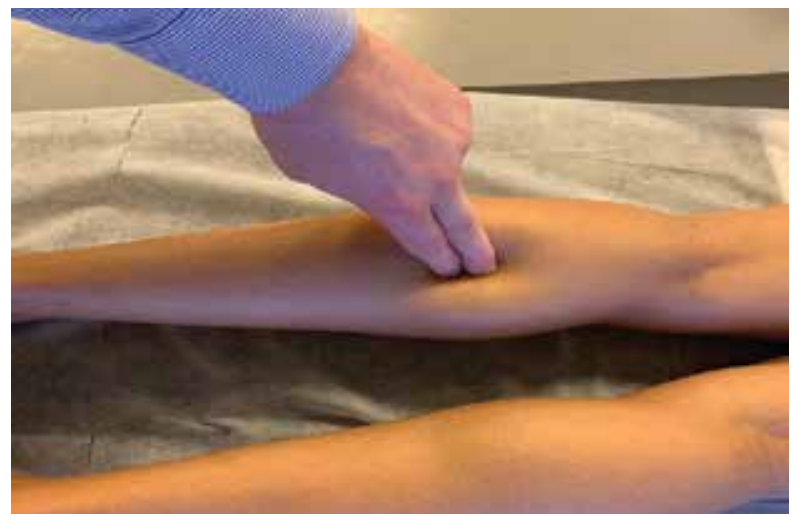

Figure 7: Tinel's test for the tibial nerve. Apply firm, ventrally directed pressure to the medial-paramedian calf 


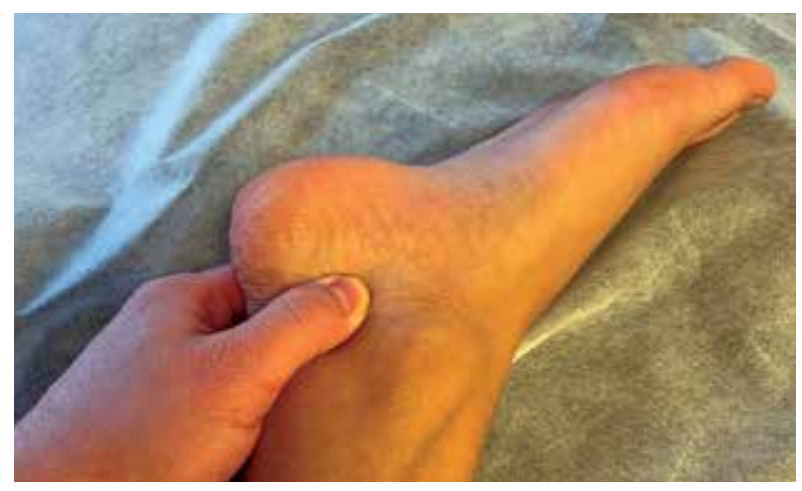

Figure 8: Tinel's test for the distal tibial nerve. Identify the tarsal tunnel immediately posteroinferior to the medial malleolus. Apply pressure medial to lateral

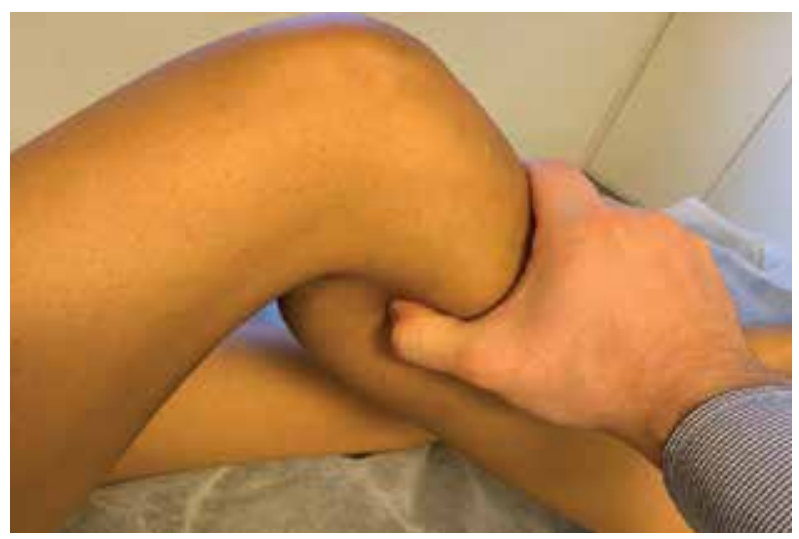

Figure 9: Tinel's test for the common peroneal nerve. Identify the near-superior portion of the fibular bone, and track the thumb slightly posterior to it. Apply medioventral pressure

which the patient presents, as lesser forms of LPES may not always produce initial exacerbation. Tinel's test will yield higher NRS scores upon follow-up examination regardless of whether or not the patient reports increase in symptoms, as the nerves are now increasingly irritated due to the workload imposed on the muscles they transmit through or adjacent to. The cumulative evidence in favor of LPES, i.e. compatible symptoms, positive clinical tests as well as the aforementioned post-exercise sequelae will suffice in placing the LPES diagnosis, as it confirms the implication of the piriformis and psoas major muscles in the genesis of the patient's symptoms.

In summary, the following criteria is proposed for the diagnosis of LPES:

- The patient's symptoms are compatible with denominators of LPES

- Tinel's test elicits $>7$ NRS on more than 5 different points

- Myotome tests reveal [at least] one weak movement, often impaired great toe extension
- Symptoms are reproduced and exacerbated within one to two weeks after initiating strengthening exercises for the psoas major and piriformis muscles, presuming they are performed correctly, and that the patient's starting state is sufficiently poor

\section{MR IMAGING}

Diagnostic imaging criteria for detection of neuropathies generally include focal fibrillar thickening with edematous high signal changes on T2w, STIR, PD-fs and similar fluid-sensitive sequences. ${ }^{82,83}$

Known passive signs of neuropathy may include

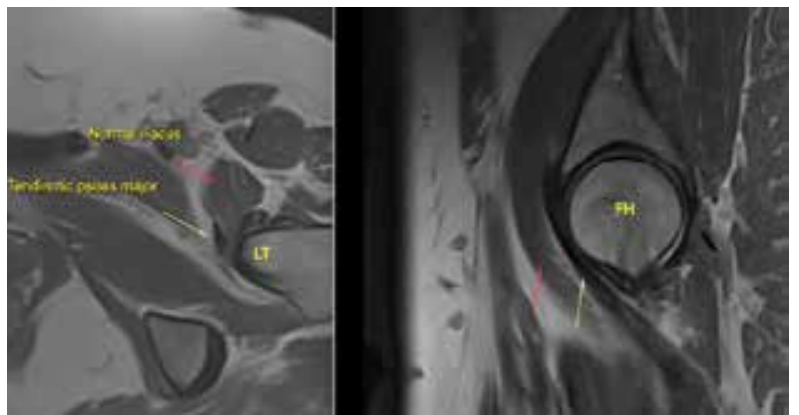

Figure 10: A 52-year-old female patient with LPES presents with hypointense (tendinotic) appearance of the psoas major (yellow arrow), but not iliacus (red arrow), implying psoas major degenerative changes. Tinel's test over the femoral, lateral femoral cutaneous, sciatic, etc., were all positive, eliciting tremendous pain. Strength testing of the psoas major revealed severe weakness, and transient exacerbation of her LPLE neuralgia developed subsequently as well, confirming the dysfunction and association. Abbreviations: LT; lesser trochanter, FH; femoral head. Sequence: Proton density

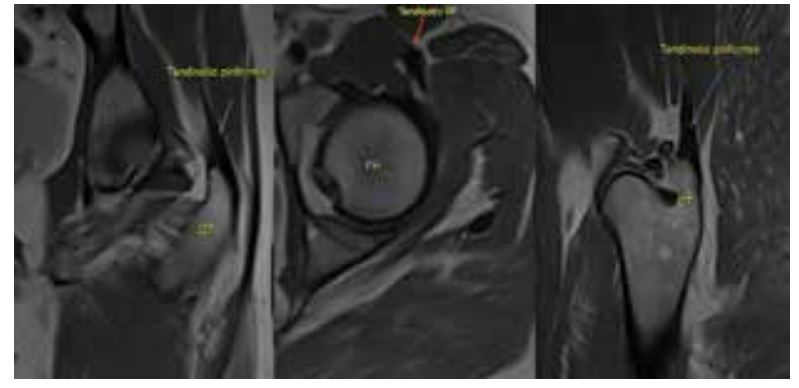

Figure 11: The same patient as in fig. 10. Hypointense signal changes of the piriformis tendon compatible with longstanding degeneration (blue arrow). Also note the tendinotic rectus femoris tendon (red arrow), which was clinically asymptomatic. Abbreviations: GT; greater trochanter, FH; femoral head, RF; rectus femoris. Sequence: Proton density 
hypertrophy or inflammation of the muscle(s) adjacent to the nerve, such as the piriformis muscle, or denervation of one or more of the entrapped nerve's innervated muscles. ${ }^{24,84,85}$ Conventionally, inflammation of a muscle or tendon is expected to exhibit a high, edematous signal upon fluid sensitive sequences, as seen in figures $12-13 .^{85}$ Chronic tendinopathies, on the other hand, are expected to demonstrate tendinous undulation and thickening, whilst chronic myopathies are identified muscular atrophy. ${ }^{86}$ Unfortunately, a systematic review by Kwee and colleagues ${ }^{87}$ found that MR neurography had heterogenous sensitivity and should not be counted as conclusive if the exam is negative. Furthermore, empirically, findings of interstitial edemae, tendinous

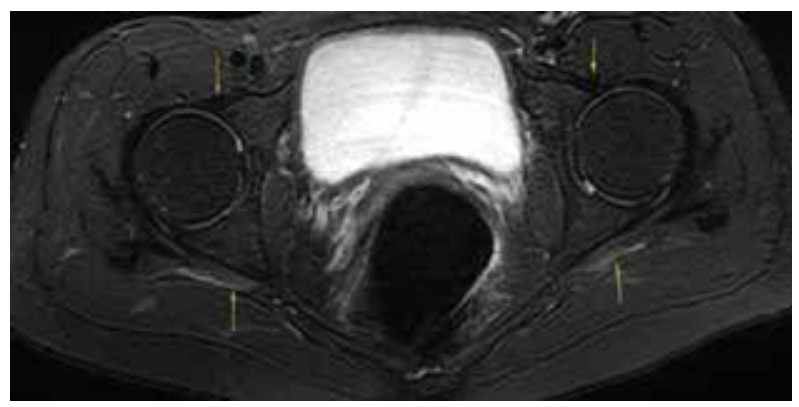

Figure 12: A 34-year-old female with LPES. Imaging reveals intramuscular edema within the psoas major (green arrow), as well as tendinous hypointensity (purple arrow) consistent with myopathy and chronic tendinosis. There are also intracapsular effusions, and the patient tested positive for anterior hip impingement. Sequence: Proton density, fatsupressed

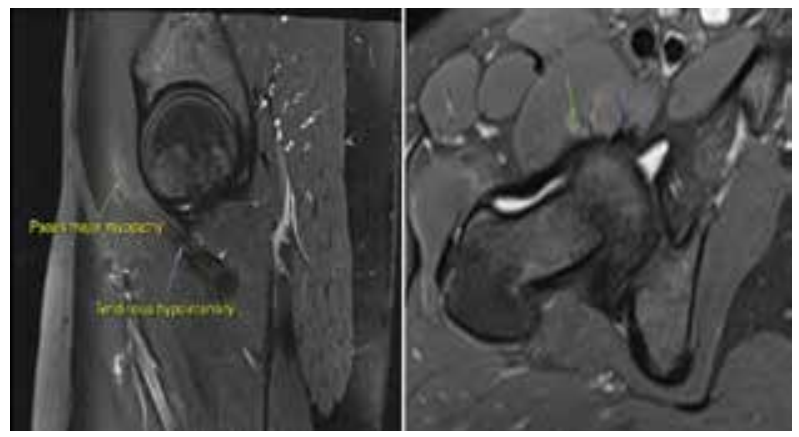

Figure 13: A 31-year-old female with LPES. Imaging reveals psoas major tendinosis as (orange arrows) as well as intramuscular edema within the piriformis muscles (green arrows). Sequence: Proton density, fat-suppressed

undulation and thickening or muscular atrophy are rarely present to a significant degree in patients with LPES, despite conspicuous clinical indications. Surely, a patient with many years of chronic pain, whose physical exam suggest severe impairment of the psoas major and piriformis muscles, should exhibit some sign of pathology upon MRI? Is MRI insensitive to chronic myotendinous impairment, or, could there be a problem with the consensual definition of regular tendinous appearance?

Indeed, there appears to be a misconception with regards to the imaging criteria of chronic tendinopathies, in specific. Normal tendons are thought to exhibit a low signal on all MR sequences. ${ }^{88}$ In strict contradiction to this, it is our experience that darkened myotendinous structures, especially on PD sequences, in reality, may imply chronic tendinosis, and not normality, as it is a consistent finding in patients with LPES. It is also our hypothesis that tendinous thickening and undulation, i.e. the consensual tendinotic indication, may be an intermediate stage of tendinous degeneration, and not necessarily its final form. The final form seems to be a state of normal thickness but with significant tendinous hypointensity as seen in the figures 1011 , while the thickened intermediate form suggests a certain amount of remaining tissue swelling and thus not a complete degeneration of the tendon. If our hypothesis is correct, although challenging the established musculoskeletal imaging paradigm, it would offer an explanation as to why many chronic LPLE pain sufferers frequently return with "normal" imaging reports. Chronic tendinosis would also explain why many of these patients frequently worsen with even minute loads imposed on the pelvic musculature, as its work capacity is obliterated due to longstanding degeneration.

Identification of this condition is, then, easiest indicated by the appearance of its tendon, and not necessarily the muscle itself. Blatant atrophy is not a common finding in LPES patients. Degenerative tendinous changes, however, are a prevalent finding on MRI. Such findings may also be coincidental and asymptomatic, especially if the affected muscle is not an acting nerve gate, such as the piriformis or the psoas major, through which the lumbar plexus and sciatic nerves transmit. It is therefore essential, as always, when interpreting the findings of imaging studies, to compare them to the patient's complaints and clinical examination.

Proton density weighted imaging with fat suppression (PD-fs) seems superior in the detection of both degenerative and inflammatory myotendinous pathologies for LPES, and should be included with axial, sagittal and coronal planes. A plain T1w axial sequence may also be included for greater sensitivity for muscular atrophy. Further research is needed to improve delineation of degenerative and normal tendinous appearances.

\section{NEUROGRAPHY}

When entrapment neuropathy is suspected, it is common practice is to rely on electroneurographic 


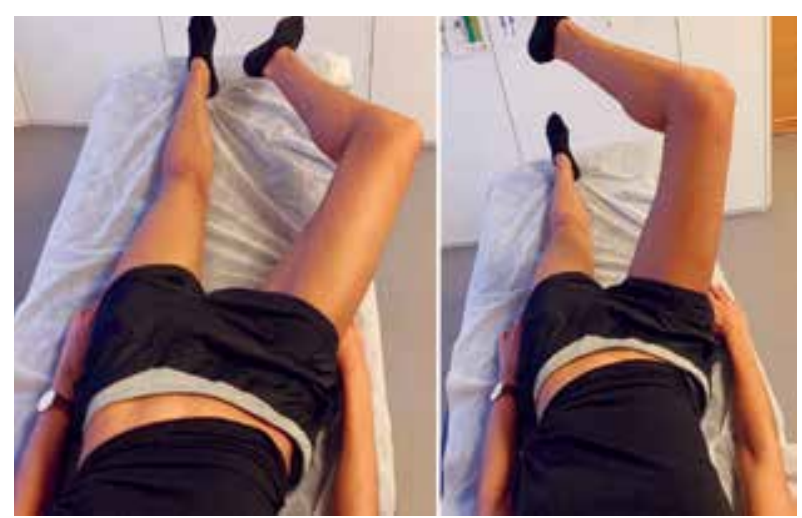

Figure 14: Psoas major muscle exercise: The patient lies supine with an arched lumbosacral spine. The knee is bent to between $90-135^{\circ}$, and the femur is slightly abducted but maximally laterally rotated. Finally, maintain these angles, most importantly the maximal lateral femoral rotation and lumbosacral lordosis, while gently pulling the lesser trochanter toward the ipsilateral abdominal flank. Elevation past $80^{\circ}$ is not beneficial, as this flattens the lumbosacral lordosis.

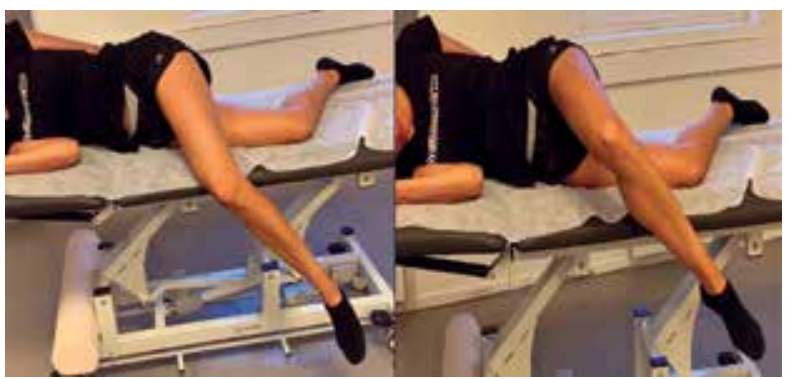

Figure 15: Piriformis muscle exercise: The patient is in lateral position, preferably on a surface with an edge. The hip is flexed to approximately $70^{\circ}$, and is maximally laterally rotated. The knee is bent between 90-135. Finally, the patient, without moving the pelvis, gently horizontally abducts the hip by pulling the «knee toward the ceiling».

Maximal hip flexion may cause a weak \& tight piriformis muscle to stretch significantly, compressing the sciatic nerve, causing local sensory numbness.

Thus, an absent Tinel's sign upon provocation of the inguinal ligament and piriformis muscles does not exclude affection of the sciatic, femoral, lateral femoral cutaneous, and genitofemoral nerves. Some simple tests may aid the clinician in distinguishing normality from occult pathology: If focal compression is suspected, this may often be easily detected, as the nerve will be profoundly tender to palpation distal to the compressed area. For instance, a hypoesthetic buttock in tandem with a severely painful intermediate sciatic or tibial nerve, suggests proximal sciatic numbness and significant compression of the nerve caused by the piriformis muscle. In such cases, [relative] myotome weakness of the L5 (great toe

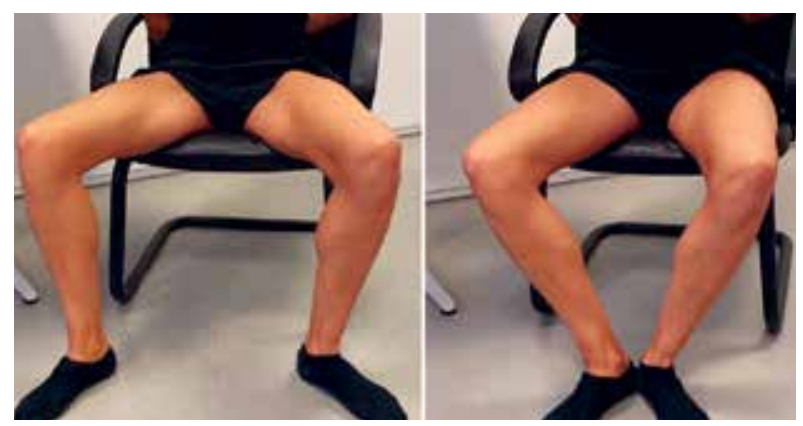

Figure 16: Musculus pectineus exercise: The patient is seated with the torso leaning slightly backward. The legs are abducted and externally rotated, and knees bent to approximately $90^{\circ}$. Gentle adduction is performed by approximating the heels while, simultaneously, maintaining lateral femoral rotation.

extension), S1 (ankle eversion) or S2 (knee flexion) may be present as well. Likewise, negative Tinel's upon provocation of the inguinal ligament (femoral nerve, LFCN \& GFN) in tandem with severe pain elicitation upon provocative pressure to the distal saphenous nerve, indicates proximal compression at the inguinal ligament, by the pectineus muscle. In this case, weakness of the L3 (knee extension) and L4 (ankle dorsiflexion) myotomes are frequent cofindings.

Regardless of whether or not focal numbness was detected during the provocative examination, lower extremity myotomes should be checked. Beware, however, that utter paresis (palsy) is not expected unless there is severe neuropathy. This is infrequent in LPES sufferers. Thus, some force should be used when performing these tests, looking for "relative weakness", as Selmonosky ${ }^{50,51,81}$ describes when searching for TOS. Hip flexion (L1-2), knee extension (L3), ankle dorsiflexion (L4) great toe extension (L5), foot eversion (S1), knee flexion (S2) are all viable tests when evaluating the severity of LPES. Compare the findings with the patient's complaints and sensory evaluation, etc., for a reliable interpretation of the whole picture. Generally, hyperesthesia comes first and weakness thereafter, depending on the severity of the case. It is also our impression that significant peripheral compression tends to cause focal sensory loss with distal hyperesthesia, whilst root compression may frequently cause hypoesthesia along the nerve's full length, but more statistical research is needed to validify this.

Finally, strength tests for the piriformis and psoas major muscles should be performed. The exercises are somewhat complicated, but when executed correctly (details in the "Treatment" section) significant weakness should be demonstrated. Further, a worsening of symptoms one to two weeks post-exercise will usually develop, but this will be somewhat dependant on the degree of initial morbidity with 
studies to provide diagnostic information. However, despite often having "textbook" neurogenic complaints and a compatible physical examination, these studies may frequently return negative or borderline (inconclusive) in patients with LPES.

Historically, several authors have reported poor sensitivity of electroneurographic (ENoG), somatosensory evoked potentials (SEP) as well as electromyography (EMG) when searching for evidence of nerve entrapment plexopathy and neuropathy. ${ }^{44,89,90,91,92,93,94,95}$ Rousseff et al. ${ }^{95}$ reported that only 2 out of 20 patients with conspicuous clinical symptoms of TOS, had positive electrodiagnostic findings, in their article "Utility (or futility?) of electrodiagnosis in thoracic outlet syndrome." Fishman et al. ${ }^{96}$ reported that EMG studies for piriformis syndrome tend to be negative in a normal resting position, but had greater sensitivity if the patient was placed in the FAIR provocative testing position. Machanic \& Sanders, ${ }^{97}$ in search of a reliable electrodiagnostic test for NTOS, found that nerve conduction velocity tests of the medial antebrachial cutaneous nerve had superior sensitivity and specificity compared to conventional criteria, which were frequently insensitive. The same was noted by Tsao, ${ }^{91}$ Kothari $^{98}$ and Seror, ${ }^{99}$ again suggesting that the traditional diagnostic tests may be insensitive. Passero et al..$^{90}$ found that SEP may have a useful value in diagnosing TOS, but found NCV of little utility. Inconsistently, studies conducted by Veilleux ${ }^{92}$ and Aminoff ${ }^{93}$ found that SEP has limited value in the diagnosis of TOS.

Certainly, electroneurographic studies may often provide important diagnostic and qualitative information, but the clinician should be aware that its findings are not necessarily conclusive when diagnosing potential entrapment neuropathies and that a negative test does not exclude LPES.

\section{TREATMENT}

The primary treatment strategy for LPES is gentle strengthening of the psoas major and piriformis muscles, as indicated several times throughout this article. It is our experience that these two structures will account for approximately $=>80 \%$ of the patient's pain generation, and are thus the main drivers of the problem. Systematic reviews and other reviews suggest that muscles affected by tendinous degeneration may best respond to specific slow and eccentric strengthening exercises, ${ }^{100,101,102,103,104,105}$ and the same approach has been found beneficial for LPES by the authors, as will be described in part two of this article series.

However, depending on the severity of the affliction, only very small workloads may be tolerated by the patient. Overburdening of the muscle tend to develop rapidly, resulting in sometimes gross exacerbation of the patient's pain. This, if not detected and regulated, often leads to demotivation and loss of patient compliance, which in the worst-case scenario may ruin the rehabilitative plan in its entirety. Empirically, overburdening may occur at such low workloads that it may seem absurd to the practitioner and patient alike. Significantly afflicted patients may require 3-7 days of restitution after mere 3-5 repetitions of the piriformis and psoas major exercises. Even at this low volume, for such a patient, significant symptom exacerbation may occur, consistent with extreme muscular weakness and work capacity deficiency. However, with patience and diligence, adequate work capacity can be restored, and the problem may be cured. Athletes whose pain only occurs during sports may frequently tolerate much greater workloads without a significant flare-up, but some exercise intensity regulation is also required in this patient group.

The exercises for these muscles are somewhat difficult to perform correctly, as demonstrated and described in figures 14-16. The psoas major and piriformis muscles may prove especially troublesome for many patients, as many compensatory movement patterns may develop after longstanding dysfunction. Some patience is necessary in order to teach the patient how to execute the movements properly. The patient should, presuming that the diagnosis and exercise execution are both correct, demonstrate significant weakness during strengthening. It is imperative to perform the movements slowly, as "jerky" movements may rapidly involve synergists, and inhibit appropriate stimulus of the psoas major and piriformis muscles. As mentioned, regarding the patients with greater initial morbidity, pain exacerbation is expected the days following exercise, and therefore it is important to start gently. 5-10 repetitions, one working set, one to three times per week, is generally a good starting point for most LPES sufferers.

If significant symptom exacerbation occurs, the patient did too many repetitions, or performed the exercises too often. Lack of compliance with regards to low work-volume is common initially, as the patient will find 5-10 repetitions "only" as an absurdly mild homework. This, however, is quickly learned "the hard way", when symptoms intensify. The clinician should make sure to explain these things thoroughly to the patient in advance, to avoid unnecessary complications. Increase and decrease in homework volume must be regulated in accordance with the patient's post-exercise symptoms. "Pushing through" the pain will rarely benefit the patient, but will instead increase inflammation and prolong restitution time, making the tissues more susceptible for further overloading and damage. Repeated myotome tests 
as well as Tinel's tests should be performed on each follow-up session, to ensure that the patient is not overdoing their exercises and inevitably making themselves worse.

If numbness of the femoral nerve was detected during physical examination, this, as mentioned, generally implies impingement of the femoral nerve during hip flexion, between the pectineus muscle and inguinal ligament. Because this problem's etiology is a positional compression, and not a continuous entrapment within the myofascial such as with the psoas major and piriformis muscles, it may be treated by 1: Strengthening the pectineus muscle, and 2: Restricting maximal hip flexion for a short period, until adequate strength and pliability has been restored to the pectineus. If the patient does not report increased pain or anterior femoral paresthesia after sitting in forward-leaning position, i.e. provocative positioning, the finding may be of lesser importance, and the clinician may decide not to periodically restrict hip flexion, despite indicated impingement. Re-evaluate later on, if indicated.

\section{LIMITATIONS}

The primary limitation of this study is the lack of LPES research. Thus, many statements in this manuscript are based on our empirical data. More research is clearly needed, especially with regards to epidemiology and other relevant statistics. Another limitation of this study was that the patient sample numbers were relatively small, and the treatment carried out in a private clinical setting and may therefore not necessarily and appropriately reflect that of the public population.

\section{CONCLUSION}

Lumbar plexus entrapment syndrome is a common problem which may involve significant morbidity, often debilitating the patient. It is caused by entrapment of the lumbosacral plexuses within the psoas major and piriformis muscles, due to severe weakness or injury of these structures. Its presentation generally involves nonspecific pain in the pelvis and lower extremities, which makes it mimic other diagnoses such as fibromyalgia or seemingly unrelated peripheral entrapments, similar to what has been reported for thoracic outlet syndrome. The protocol for identification of LPES involves a compatible patient history, along with abnormally high pain elicitations upon pressure to several of the nervous branches of the LPLE. Myotome weakness, especially of great toe extension, is often present. Further, reproduction of the patient's symptoms as well as increased pain elicitation upon Tinel's test after commencing appropriate rehabilitation, may be viewed as "nail in the coffin"-confirmatory. MRI may reveal a tendinotic, hypointense appearance of the psoas major and piriformis tendons.

The rehabilitation for LPES involves specific, gentle strengthening exercises for the psoas major and piriformis muscles with very low workloads, gradually increasing the muscles' work capacities over the course of time. It is a safe, inexpensive and relatively simple treatment that may be carried out by the patient him- or herself within the comfort of their own homes. However, for patients with greater morbidity, patience is required, as it takes time to resolve the condition. Further, the patient must pay attention to detail, as well as regulate their exercise intensity to avoid excess stimulus of the impaired musculature, as this will completely stunt progress, which may lead to loss of patient compliance and thus also the absence of recovery. Rehabilitative trials will be documented in part two of this article series.

Conflict of interest: Nil

Authors' contribution: Both authors took part in the conduct or study, preparation of the manuscript and literature search. 


\section{REFERENCES}

1. Ahangaria A. Prevalence of chronic pelvic pain among women: an updated review. Pain Physician. 2014;17(2):141-7. [PubMed]

2. Laslett M. Evidence-based diagnosis and treatment of the painful sacroiliac joint. J Man Manip Ther. 2008;16(3):142-52. [PubMed]

3. Vleeming A, Schuenke MD, Masi AT, Carreiro JE, Danneels L, Willard FH. The sacroiliac joint: an overview of its anatomy, function and potential clinical implications. J Anat. 2012;221(6):537-67. [PubMed]

4. Nachemson A. Newest knowledge of low back pain: a critical look. Clin Orthop Relat Res. 1992;279:8-20. [PunMed]

5. Cyriax JH. Textbook of Orthopedic Medicine. 11th ed. Bailliere Tindall 1984 Feb 26.

6. As-Sanie S, Harris RE, Harte SE, Tu FF, Neshewat G, Clauw DJ. Increased pressure pain sensitivity in women with chronic pelvic pain. Obstet Gynecol. 2013;122(5):1047-55. [PubMed]

7. Tinel J. Le signe du fourmillement dans les lésions des nerfs périphériques. Presse médicale. 1915:47:388-389.

8. Larsen K. How to identify and treat lumbar plexus compression syndrome (LPCS). Web blog. Available on https://treningogrehab.no/identifytreat-lumbar-plexus-compressionsyndrome-Ipcs/. (Accessed on 2018 Oct 19)

9. Twydell PT. Lumbosacral plexus syndromes. Available on https://www. uptodate.com/contents/lumbosacralplexus-syndromes. (Accessed on 2018 0ct 19)

10. Chevalier $X$, Larget-Piet B. Femoral neuropathy due to psoas hematoma revisited. Report of three cases with serious outcomes. Spine (Phila Pa 1976). 1992;17(6):724-6. [PubMed]

11. Ozkan OF, Guner A, Cekic AB, Turan T, Kaya U, Reis E. Iliopsoas haematoma: a rare complication of warfarin therapy. J Coll Physicians Surg Pak. 2012;22(10):673-4. [PubMed] DOI:
10.2012/JCPSP.673674

12. Batchelor TJ, Vowden P. A persistent sciatic artery aneurysm with an associated internal iliac artery aneurysm. Eur J Vasc Endovasc Surg. 2000;20(4):400-2. [PubMed]

13. Stewart JD. "Foot drop: where, why and what to do?" Pract Neurol. 2008;8(3):158-169. [PubMed] DOl: 10.1136/jnnp.2008.149393

14. Griffiths EA, Kalbassi MR, Cunliffe WJ, Browell DA. Psoas abscess as a secondary complication of gastrointestinal disease: report of five cases. Case Rep Clin Pract Rev. 2003;4(2):73-6.

15. Yeo PT, Grice AC. Lumbosacral nerve plexus compression by ovarianfallopian cysts. Clin Exp Neurol. 1986;22:139-43. [PubMed]

16. Jaeckle KA, Young DF, Foley KM. The natural history of lumbosacral plexopathy in cancer. Neurology. 1985;35(1):8-15. [PubMed] DOI: https://doi.org/10.1212/wnl.35.1.8

17. Stevens MJ, Gonet YM. Malignant psoas syndrome: recognition of an oncologic entity. Australas Radiol. 1990;34(2):150-4. [PubMed]

18. Irvin W, Andersen W, Taylor P, Rice L. Minimizing the risk of neurologic injury ingynecologic surgery. ObstetGynecol. 2004;103(2):374-82. [PubMed] DOl: $\quad$ https://doi.org/10.1097/01. A0G.0000110542.53489.c6

19. Kirchmair L, Lirk P, Colvin J, Mitterschiffthaler G, Moriggl B. Lumbar plexus and psoas major muscle: not always as expected. Reg Anesth Pain Med. 2008;33(2):109-14. [PubMed] DOI: 10.1016/j.rapm.2007.07.016

20. Anloague PA, Huijbregts P. Anatomical variations of the lumbar plexus: a descriptive anatomy study with proposed clinical implications. J Man Manip Ther. 2009;17(4):107-14. DOl: https://www.tandfonline.com/doi/ abs/10.1179/106698109791352201

21. Whitaker R, Borley N. Chapter 6 . Instant anatomy. 1st ed. Oxford: Blackwell Scientific. 1994;114-23.

22. Smoll NR. Variations of the piriformis and sciatic nerve with clinical consequence: a review. Clin Anat. 2010;23(1):8-17. [PubMed] DOl: 10.1002/ca.20893

23. Tomaszewiski KA, Graves MJ, Henry BM, Popieluszko P, Roy J, Pekala PA, et al. Surgical anatomy of the sciatic nerve: A meta-analysis. J Orthop Res. 2016;34(10):1820-1827. [PubMed] DOI: $\quad$ https://doi.org/10.1002/ jor.23186

24. Hopayian K, Song F, Riera R, Sambandan $S$. The clinical features of the piriformis syndrome: a systematic review. Eur Spine J. 2010;19(12):2095-2109. [PubMed] DOI: 10.1007/s00586-010-1504-9

25. Molinari WJ, Elfar JC. The double crush syndrome. J Hand Surg Am. 2013;38(4):799-801. [PubMed] DOl: $\quad$ https://doi.org/10.1016/j. jhsa.2012.12.038

26. Upton AR, McComas AJ. The double crush in nerve entrapment syndromes. Lancet. $\quad$ 1973;2(7825):359-62. [PubMed]

27. Hurst LC, Weissberg D, Carroll RE. The relationship of double crush syndrome to carpal tunnel syndrome (Analysis of 1,000 cases of carpal tunnel syndrome). J Hand Surg. 1985:10(B);202-204. [PubMed]

28. Osterman AL. The double crush syndrome. Orthop Clin North Am. 1988;19(1);147-155. [PubMed]

29. Kane PM, Daniels AH, Akelman E. Double crush syndrome. J Am Acad Orthop Surg. 2015;23(9):55862. [PubMed] DOI: 10.5435/ JAAOS-D-14-00176

30. Merrill CA, Ferreira J, Parrino A, Moss IL. Team approach: upperextremity numbness. JBJS Rev. 2018;6(6):e3. [PubMed] D0l: https:// doi.org/10.2106/JBJS.RVW.17.00166

31. Cohen BH, Gaspar MP, Daniels $A H$, Akelman E, Kane PM. Multifocal Neuropathy: Expanding the scope of double crush syndrome. J Hand Surg Am. 2016;41(12):1171-1175. [PubMed]

32. Toussaint CP, Ali ZS, Heuer GG, Zager 
EL. "Double crush syndrome" in thoracic outlet syndrome. SpringerVerlag. 2013;101-104. Available at: https://www.handsurgeryresource. com/double-crush (Accessed on 18 November 2018)

33. Morgan G, Wilbourn AJ. Cervical radiculopathy and coexisting distal entrapment neuropathies: doublecrush syndromes? Neurology. 1998;50(1):78-83. [PubMed]

34. Baba M, Ozaki I, Watahiki Y, Kudo M, Takebe K, Matsunaga M. Focal conduction delay at the carpal tunnel and the cubital fossa in diabetic polyneuropathy. Electromyogr Clin Neurophysiol. 1987;27(2):119-23. PMID: 3582257. [PubMed]

35. Maigne R. Low back pain of thoracolumbar origin. Arch Phys Med Rehabil. 1980;61(9):389-395. [PubMed]

36. DiMond ME. Rehabilitative principles in the management of thoracolumbar syndrome: a case report. Journal of Chiropractic Medicine. 2017;16(4):331-339. [PubMed] DOl:10.1016/j.jcm.2017.10.003

37. Bokgduk N. Lumbar dorsal ramus syndrome. Med J Aust. 1980;2(10):537-41. [PubMed]

38. Maigne JY, Maigne R. Trigger point of the posterior iliac crest: painful iliolumbar ligament insertion or cutaneous dorsal ramus pain? An anatomic study. Arch Phys Med Rehabil. 1991;72(10):734-7. [PubMed]

39. Anderson-Jones SR, Zhang T, Trescot AM. Lumbar plexus entrapment: Pelvic. Springer Peripheral Nerve Entrapments 2016;527-543. Available at: https://www.researchgate.net/ publication/302912406_Lumbar_ Plexus_Entrapment_Pelvic (Accessed on 18 November 2018)

40. Rassner L. Lumbar plexus nerve entrapment syndromes as a cause of groin pain in athletes. Curr Sports Med Rep. 2011;10(2):11520. [PubMed] DOI: 10.1249/ JSR.0b013e318214a045

41. Hooper TL, Denton J, McGalliard MK,
Brismée JM, Sizer PS Jr. Thoracic outlet syndrome: a controversial clinical condition. Part 1: anatomy, and clinical examination/diagnosis. J Man Manip Ther. 2010;18(2):74-83. [PubMed] DOl: 10.1179/106698110 X12640740712734

42. Palmer OP, Weaver FA. Bilateral cervical ribs causing cerebellar stroke and arterial thoracic outlet syndrome: a case report and review of the literature. Ann Vasc Surg. 2015;29(4):840.e1-4. [PubMed] D0l: 10.1016/j.avsg.2014.12.008

43. Foley JM, Finlayson H, Travlos A. A review of thoracic outlet syndrome and the possible role of botulinum toxin in the treatment of this syndrome. Toxins (Basel). 2012;4(11):122335. [PubMed] DOl:10.3390/ toxins4111223

44. Boezaart AP, Haller A, Laduzenski $S$, Koyyalamudi VB, Innatsenka B, Wright T. Neurogenic thoracic outlet syndrome: a case report and review of the literature. Int $\mathrm{J}$ Shoulder Surg. 2010;4(2):27-35. [PubMed] D0l:10.4103/0973-6042.70817

45. Atasoy E. Thoracic outlet compression syndrome. Orthop Clin North Am. 1996;27(2):265-303. [PubMed]

46. Povlsen B, Hansson T, Povlsen SD. Treatment for thoracic outlet syndrome. Cochrane Database Syst Rev. 2014;(11):CD007218. [PubMed] DOI: $10.1002 / 14651858 . C D 007218$. pub3

47. Redman L, Robbs J. Neurogenic thoracic outlet syndrome: are anatomical anomalies significant? S Afr J Surg. 2015;53(1):22-5. [PubMed]

48. Köknel TG. Thoracic outlet syndrome. Agri. 2005;17(2):5-9. [PubMed]

49. Nakano KK. The entrapment neuropathies of rheumatoid arthritis. Orthop Clin North Am. 1975 Jul;6(3):837-60. [PubMed]

50. Selmonosky CA, Byrd R, Blood C, Blanc JS. Useful triad for diagnosing the cause of chest pain. South Med J. 1981;74:974-949. [PubMed]

51. Selmonosky CA, Poblete Silva R. The diagnosis of thoracic outlet syndrome. Myths and Facts. Chilean J of Surg. 2008;60(3):255-261.

52. Lindgren KA, Leino $\mathrm{E}$, Manninen $\mathrm{H}$. Cervical rotation lateral flexion test in brachialgia. Arch Phys Med Rehabil. 1992;73(8):735-7. [PubMed]

53. Chen D, Gu Y, Lao J, Chen L. Dorsal scapular nerve compression. Atypical thoracic outlet syndrome. Chin Med J (Engl). 1995;108:582-5. [PubMed]

54. Urschel HC, Kourtis H. Thoracic outlet syndrome: a 50 year experience at Baylor University Medical Center. Proc (Bayl Union Med Cent). 2007;20(2):125-35.

55. Kaymak B, Ozcakar L. Complex regional pain syndrome in thoracic outlet syndrome. Br J Sports Med. 2004;38(3):364. [PubMed] DOI: [10.1136/bjsm.2004.012062]

56. Broadhurst NA, Simmons DN, Bond MJ. Piriformis syndrome: correlation of muscle morphology with symptoms and signs. Arch Phys Med Rehabil. 2004;85:2036-2039. [PubMed]

57. Chen WS, Wan YL. Sciatica caused by piriformis muscle syndrome: report of two cases. J Formos Med Assoc. 1992;91:647-650. [PubMed]

58. Pecina HI, Boric I, Smoljanovic T, Duvancic D, Pecina M. Surgical evaluation of magnetic resonance imaging findings in piriformis muscle syndrome. Skeletal Radiol. 2008;37:1019-1023. [PubMed]

59. Turtas S, Zirattu G. The piriformis syndrome: a case report of an unusual cause of sciatica. J Orthop Traumatol. 2006;7:97-99.

60. Vanti C, Natalini L, Romeo A, Tosarelli D, Pillastrini P. Conservative treatment of thoracic outlet syndrome. A review of the literature. Eura Medicophys. 2007;43(1):55-70. [PubMed]

61. Machleder HI, Moll F, Verity A. The anterior scalene muscle in thoracic outlet compression syndrome. Arch Surg. 1986;121(10):11411144. [PubMed] Dol:10.1001/ archsurg.1986.01400100047009

62. Qaja E, Honari S, Rhee R. Arterial thoracic outlet syndrome secondary 
to hypertrophy of the anterior scalene muscle. J Surg Case Rep. 2017; 2017(8):rjx158. [PubMed] DOl: [10.1093/jscr/rjx158]

63. Bortolani E, Miani S, D'Armini A, Gallo $E$, Morbidelli A. Role of anterior scalene muscle hypertrophy in thoracic outlet syndrome. Minerva Chir. 1989;44(8):1305-9. [PubMed]

64. Yürük D, Özgencil GE, Yılmaz A, Kocaoğlu MH, Bilgin SS, Aşık I. Thoracic outlet syndrome: a case of scalene muscle hypertrophy in longterm follow-up of diagnosis of cervical discopathy. Agri. 2016;28(3):158161. [PubMed] DOI: 10.5505/ agri.2015.20981

65. Axelrod DA, Proctor MC, Geisser ME, Roth RS, Greenfield LJ. Outcomes after surgery for thoracic outlet syndrome. J Vasc Surg. 2001;33(6):1220-5. [PubMed]

66. Christo PJ, McGreevy K. Updated perspectives on neurogenic thoracic outlet syndrome. Curr Pain Headache Rep. 2011;15(1):14-21. [PubMed] DOI: 10.1007/s11916-010-0163-1.

67. Altobelli GG, Kudo T, Haas BT, Chandra FA, Moy JL, Ahn SS. Thoracic outlet syndrome: pattern of clinical success after operative decompression. J Vasc Surg. 2005;42(1):122-128. [PubMed] DOl: $\quad$ https://doi.org/10.1016/j. jvs.2005.03.029

68. Maxey TS, Reece TB, Ellman PI, Tribble CG, Harthun N, Kron IL, et al. Safety and efficacy of the supraclavicular approach to thoracic outlet decompression. Ann Thorac Surg. 2003;76(2):396-9. discussion 399-400. [PubMed] [Free full text]

69. Barkhordarian S. First rib resection in thoracic outlet syndrome. J Hand Surg Am. 2007;32(4):565-70. [PubMed]

70. Scheper MC, de Vries JE, Verbunt $\mathrm{J}$, Engelbert $\mathrm{RH}$. Chronic pain in hypermobility syndrome and ehlersdanlos syndrome (hypermobility type): it is a challenge. J Pain Res. 2015;8:591-601. [PubMed] DOI: 10.2147/JPR.S64251

71. Kumar B, Lenert P. Joint hypermobility syndrome: recognizing a commonly overlooked cause of chronic pain.
Am J Med. 2017;130(6):640-647. [PubMed] DOI: 10.1016/j.amjmed

72. Langevin HM, Stevens-Tuttle D, Fox JR, Badger GJ, Bouffard NA, Krag MH, et al. Ultrasound evidence of altered lumbar connective tissue structure in human subjects with chronic low back pain. BMC Musculoskelet Disord. 2009;10:151. [PubMed] DOl:10.1186/1471-2474-10-151

73. De Pauw R, Coppieters I, Kregel J, De Meulemeester K, Danneels L, Cagnie B. Does muscle morphology change in chronic neck pain patients? - A systematic review. Man Ther. 2016;22:42-9. [PubMed] DOI: 10.1016/j.math.2015.11.006

74. Sanders RJ, Jackson CG, Banchero $\mathrm{N}$, Pearce WH. Scalene muscle abnormalities in traumatic thoracic outlet syndrome. Am J Surg. 1990;159(2):231-6. [PubMed]

75. Elliott J, Jull G, Noteboom JT, Darnell R, Galloway G, Gibbon WW. Fatty infiltration in the cervical extensor muscles in persistent whiplashassociated disorders: a magnetic resonance imaging analysis. Spine (Phila Pa 1976). 2006;31(22):84755. [PubMed]

76. Wan Q, Lin C, Li X, Zeng W, Ma C. MRI assessment of paraspinal muscles in patients with acute and chronic unilateral low back pain. $\mathrm{Br} \mathrm{J}$ Radiol. 2015;88(1053):20140546. [PubMed]

77. Stecco A, Meneghini A, Stern $R$, Stecco C, Imamura M. Ultrasonography in myofascial neck pain: randomized clinical trial for diagnosis and follow-up. Surg Radiol Anat. 2014;36(3):243-53. [PubMed] DOI: $10.1007 / \mathrm{s} 00276-013-1185-2$.

78. Stecco C, Stern R, Porzionato A, Macchi V, Masiero S, Stecco A, et al. Hyaluronan within fascia in the etiology of myofascial pain. Surg Radiol Anat. 2011;33(10):891-6. [PubMed] DOI: 10.1007/s00276-011-0876-9

79. Massoud AA, Reza MN, Mohammadifar A. The relationship between hamstring length and gluteal muscle strength in individuals with sacroiliac joint dysfunction. J Man Manip Ther. 2011;19(1):5-10. [PubMed] D0l:10.1
179/106698110X12804993426848

80. Mooney V, Pozos R, Vleeming A, Gulick $\mathrm{J}$, Swenski D. Exercise treatment for sacroiliac pain. Orthopedics. 2001;24(1):29-32. [PubMed]

81. Selmonosky CA. The white hand sign. A new single maneuver useful in the diagnosis of thoracic outlet syndrome. Southern Med Journal. 2002;85:557. Link: http://www.tos-syndrome.com/ Diag_of_TOS.htm

82. Chhabra A, Andreisek G, Soldatos T, Wang KC, Flammang AJ, Belzberg AJ, et al. MR neurography: past, present, and future. AJR Am J Roentgenol. 2011;197(3):583-591. [PubMed] doi: 10.2214/AJR.10.6012.

83. Muniz Neto FJ, Kihara Filho EN, Miranda FC, Rosemberg LA, Santos DCB, Taneja AK. Demystifying MR neurography of the lumbosacral plexus: from protocols to pathologies. BioMed Research International. Volume 2018, Article ID 9608947, 20 pages. DOI: https://doi. org/10.1155/2018/9608947

84. Rossi P, Cardinali P, Serrao M, Parisi L, Bianco F, De Bac S. Magnetic resonance imaging findings in piriformis syndrome: a case report. Arch Phys Med Rehabil. 2001;82(4):519-21. [PubMed]

85. Vilanova JC, García-Figueiras $\mathrm{R}$, Luna A, Baleato-González S, Tomás $X$, Narváez JA. Update onWhole-y $\mathrm{MRI}$ in Musculoskeletal Applications. Semin Musculoskelet Radiol. 2019 Jun;23(3):312-323. doi: 10.1055/s-0039-1685540 [PubMed] 86. Theodorou DJ, Theodorou SJ, Kakitsubata Y. Skeletal muscle disease: patterns of MRI appearances. $\mathrm{Br} J$ Radiol. 2012;85(1020):1298308. [PubMed]

87. Kwee RM, Chhabra A, Wang KC, Marker DR, Carrino JA. Accuracy of $M R I$ in diagnosing peripheral nerve disease: a systematic review of the literature. AJR Am J Roentgenol. 2014;203:1303-09. [PubMed]

88. Hodgson RJ, O'Connor PJ, Grainger AJ. Tendon and ligament imaging. $\mathrm{Br} J$ Radiol. 2012;85(1016):11571172. [PubMed] DOI: 10.1259/ 
original article

bjr $/ 34786470$

89. Sanders RJ, Hammond SL, Rao NM. Thoracic outlet syndrome: a review. Neurologist. 2008;14(6):365-73. [PubMed] D0l: 10.1097/NRL.0b013e318176b98d

90. Passero S, Paradiso C, Giannini F, Cioni R, Burgalassi L, Battistini N. Diagnosis of thoracic outlet syndrome. Relative value of electrophysiological studies. Acta Neurol Scand. 1994:90:179-185. [PubMed]

91. Tsao BE, Ferrante MA, Wilbourn AJ, Shields RW. Electrodiagnostic features of true neurogenic thoracic outlet syndrome. Muscle Nerve. 2014;49(5):724-7. [PubMed] DOI: https://doi.org/10.1002/mus.24066

92. Veilleux M, Stevens JC, Campbell JK. Somatosensory evoked potentials: lack of value for diagnosis of thoracic outlet syndrome. Muscle Nerve. 1988;11:571-575. [PubMed]

93. Aminoff MJ, Olney RK, Parry GJ, Raskin NH. Relative utility of different electrophysiologic techniques in the evaluation of brachial plexopathies. Neurology. 1988;38:546-549. [PubMed]

94. Komanetsky RM, Novak CB, Mackinnon SE, Russo MH, Padberg AM, Louis S. Somatosensory evoked potentials fail to diagnose thoracic outlet syndrome. J Hand Surg Am. 1996;21(4):662-6. [PubMed]

95. Rousseff R, Tzvetanov P, Valkov I. Utility (or futility?) of electrodiagnosis in thoracic outlet syndrome. Electromyogr Clin Neurophysiol. 2005;45(3):131-3. [PubMed]

96. Fishman LM, Dombi GW, Michaelsen C, Ringel S, Rozbruch J, Rosner B, et al. Piriformis syndrome: diagnosis, treatment, and outcome -a 10 year study. Arch Phys Med Rehabil. 2002;83(3):295-301. [PubMed]

97. Machanic BI, Sanders RJ. Medial antebrachial cutaneous nerve measurements to diagnose neurogenic thoracic outlet syndrome. Ann Vasc Surg. 2008;22(2):248-54. [PubMed]
DOI: 10.1016/j.avsg.2007.09.009

98. Kothari MJ, Macintosh K, Heistand M, Logigian EL. Medial antebrachial cutaneous sensory studies in the evaluation of neurogenic thoracic outlet syndrome. Muscle Nerve. 1998;21:647-649. [PubMed]

99. Seror 0. Medial antebrachial cutaneous nerve conduction study, a new tool to demonstrate mild lower brachial plexus lesions. A report of 16 cases. Clin Neurophysiol. 2004;115:2316-2322. [PubMed]

100. Murtaugh B, Ihm JM. Eccentric training for the treatment of tendinopathies. Current Sports Med Rep. 2013;1537-890X/1203/175Y182 [PubMed]

101. Andres BM, Murrell GAC. Treatment of tendinopathy: what works, what does not, and what is on the horizon. Clin Orthop Relat Res. 2008;466(7):1539-1554. [PubMed] D0I:10.1007/ s11999-008-0260-1

102. Camargo PR, Alburquerque-Sendín F, Salvini TF. Eccentric training as a new approach for rotator cuff tendinopathy: review and perspectives. World J Orthop. 2014;5(5):634644. [PubMed] D0l:10.5312/wjo.v5.i5.634

103. Habets $B$, Van Cingel RE. Eccentric exercise training in chronic mid-portion achilles tendinopathy: a systematic review on different protocols. Scand J Med Sci Sports. 2015;25(1):315. [PubMed] DOI: $10.1111 / \mathrm{sms} .12208$

104. Magnussen RA, Dunn WR, Thomson AB. Nonoperative treatment of mid portion achilles tendinopathy: a systematic review. Clin J Sport Med. 2009;19(1):54-64. [PubMed] DOI: 10.1097/JSM.0b013e31818ef090

105. Ortega-Castillo M, Medina-Porqueres I, Cantero-Tellez R. A Systematic, critical review of the literature to evaluate the effectiveness of the eccentric training in symptomatic upper limb tendinopathies. J Yoga Phys Ther. 2015;5:193. DOl:10.4172/2157-7595.1000193. [Free full text] 